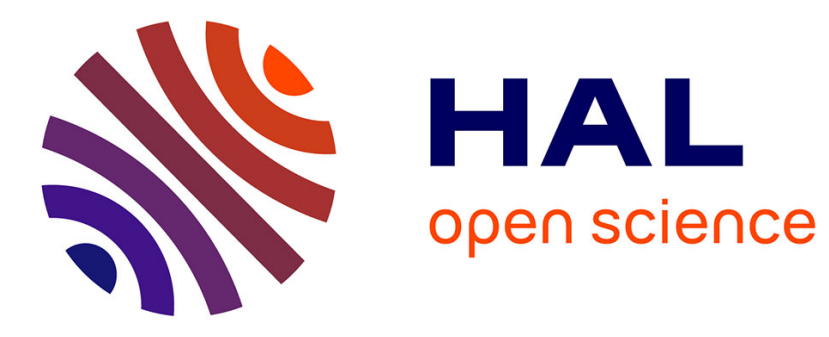

\title{
Widget and Smart Devices. A Different Aproach for Online Learning Scenarios
}

Elio San Cristobal Ruiz, Pablo Orduña, Mohamed Tawfik, Félix García Félix, Olga Dziabenko, Diego López-De-Ipiña, Christophe Salzmann, Denis Gillet, Javier García-Zubia, Catalina Martinez-Mediano, et al.

\section{To cite this version:}

Elio San Cristobal Ruiz, Pablo Orduña, Mohamed Tawfik, Félix García Félix, Olga Dziabenko, et al.. Widget and Smart Devices. A Different Aproach for Online Learning Scenarios. Proceedings of the 4th IEEE Global Engineering Education Conference (EDUCON), Mar 2013, Berlin, Germany. hal-00994907

\section{HAL Id: hal-00994907 https://telearn.archives-ouvertes.fr/hal-00994907}

Submitted on 22 May 2014

HAL is a multi-disciplinary open access archive for the deposit and dissemination of scientific research documents, whether they are published or not. The documents may come from teaching and research institutions in France or abroad, or from public or private research centers.
L'archive ouverte pluridisciplinaire HAL, est destinée au dépôt et à la diffusion de documents scientifiques de niveau recherche, publiés ou non, émanant des établissements d'enseignement et de recherche français ou étrangers, des laboratoires publics ou privés. 


\title{
Widget and Smart Devices. A Different Aproach for Online Learning Scenarios
}

\author{
Elio Sancristobal ${ }^{1}$, Pablo Orduña ${ }^{3}$, Mohamed Tawfik ${ }^{1}$, Félix García ${ }^{1}$, Olga Dziabenko ${ }^{4}$, Diego López-de-Ipiña ${ }^{3}$,Christophe \\ Salzmann $^{5}$, Denis Gillet ${ }^{5}$, Javier García-Zubia ${ }^{4}$, Catalina Martinez-Mediano ${ }^{2}$, Gabriel Díaz ${ }^{1}$, Manuel Castro ${ }^{1}$ \\ ${ }^{1}$ Electrical and Computer Engineering Department (DIEEC), Spanish University for Distance Education \\ ${ }^{2}$ MIDE-I - Spanish University for Distance Education (UNED) \\ ${ }^{3}$ Deusto Institute of Technology, University of Deusto \\ ${ }^{4}$ University of Deusto \\ ${ }^{5}$ École Polytechnique Fédérale De Lausanne
}

\begin{abstract}
A vast number of learning content and tools can be found over Internet. Currently, most of them are ad-hoc solutions which are developed for a particular learning platform or environment. New concepts, such as Widgets, Smart devices, Internet of Thing and learning Clouds, are ideas whose goals is the creation of shareable online learning scenarios over different devices and environments.
\end{abstract}

Keywords- Distance Learning, Learning Standards, Virtual and Remote labs, Smart Devices.

\section{INTRODUCTION}

Until the last decades, distance learning is based on traditional communication means, such as mail, phone, books cassettes and tapes. The appearance of Internet and the World Wide Web allowed students and teacher to work with Web pages, e-mail and electronic video and audio files through Web browser. Normally, these Web pages were composed by static content. The evolution of communication networks and protocols, and the advance of programming languages made easier the introduction of interactive content and e-learning tools. Currently, these e-learning tools are being used in distance learning, such as:

- Open courseware a set of e-learning resources (elearning content, test, other materials) in an established order [1].

- Learning management systems or LMS are a set of services that allow displaying theoretical content in an organized and controlled way. Also it is able to fulfill with e-learning standards such as Sharable Content Object Reference Model (SCORM) [2] or IMS Common Cartridge (IMS-CC) [3]

- Virtual labs are software of simulation that allows students can carry out experiments from their home.

- Remote labs are applications that allow students to work with real instruments. In the case of remote web labs, students hand the instruments through Internet [34].

Normally, all these e-learning tools were designed for Web browser and PCs. Nowadays, this is changing; new devices such as tablets and smart phones are important elements to display educational content. Also concepts such as smart devices [5], internet of thing [6] and cloud computing are modifying the way of working. This paper is focused on this issue.

As it was mentioned, it is possible to find a vast number of e-learning tools and content over Internet. These are usually organized to create online learning scenarios or activities [7-8]. The main problem is that these scenarios are ad-hoc solution and their components are developed for a particular device or e-learning system. To avoid this, e-learning standards such as:

- Content e-learning standards (SCORM or IMS-CC) provide a set of normative to pack learning content in an organized way. This learning package can be deployed in a learning management system.

- Widgets. According to W3C World Wide Web Consortium (W3C), widgets are client-side applications that are authored using Web standards such as HTML and packaged for distribution. They are typically downloaded and installed on a client machine or device where they run as stand-alone applications, but they can also be embedded into Web pages and run in a Web browser. These can create complex applications that pull data from multiple sources to be "mashed-up" and presented to a user in some interesting and useful way (http://www.w3.org/TR/widgets/). These widgets can be combined to create online learning scenarios and activities which can be displayed in different devices, such as smart phones, tables, web browser and PCs.

- $\quad$ The Smart drive device paradigm [9-10]. Physically, the considered smart device is made of the adjunction of a controlling computer the server connected to physical equipment on one the server side and connected to the Internet on the other side. A smart device has enough intelligence to communicate and adapt to any clients and it is also capable of adaptation to its surrounding (Fig 1.).

This paradigm is being considered by organization such as IEEE that is working in IEEE1451. This is not an e-learning standard, but it is a step forward in the concept of smart objects and the future use of them in 
e-learning field. This set of standards makes it easier for transducer manufacturers to develop smart devices and to interface those devices to networks, systems, and instruments by incorporating existing and emerging sensor- and networking technologies (http://www.nist.gov/el/isd/ieee/ieee1451.cfm)

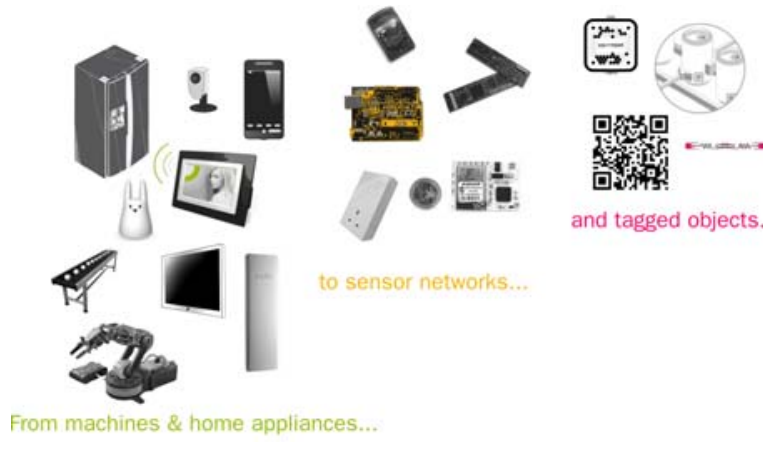

Figure 1. Example of Smart Devices.

The application of these e-learning standards allow the reuse of e-learning content and activities over Internet and provide teachers a new approach to create learning scenarios which can be implemented on different devices and platforms.

\section{DESCRIPTION AND INITIATIVES TO REUSE REMOTE LABS IN LEARNING ENVIROMENTS}

Currently it is possible to find a vast number of universities and institutions which are developing remote labs [11]. These are usually a set of instruments physically linked one of each other through buses or USB connectors (Fig. 2) that display over Internet a set of experiment which can be carried out by students out of traditional classrooms.

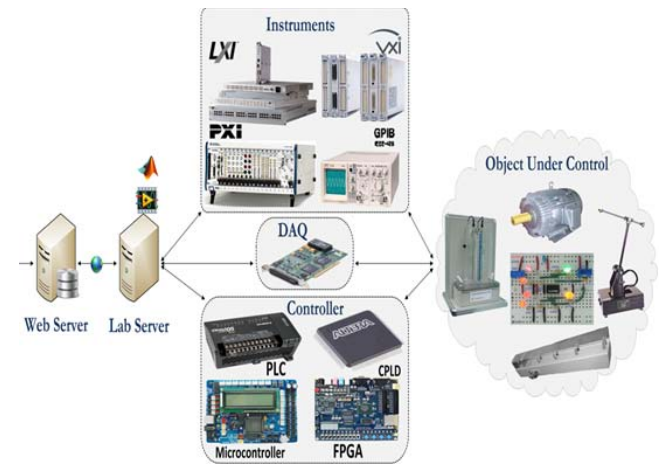

Figure 2. Remote lab architecture

According to Hardward [12] "we learned that developing new labs from scratch required considerable effort and that the domain specialist, only under rare circumstances a software engineer, had to play a key role". To make easier the development and reuse of remote labs several initiatives emerged in the last two decades:

- LabShare is led by the University of Technology, Sydney, and is a joint initiative of the Australian Technology Network: Curtin University of
Technology, Queensland University of Technology, RMIT University, University of South Australia, and the University of Technology, Sydney [13]. This project aims to create a national network of shared remotely accessible Laboratories. This mean a greater number of high-quality laboratory-based educational experiments are available to university and high school students from anywhere in Australia and around the world.

- The WebLab-Deusto project is an open source project providing a web-based, experiment-agnostic, scalable software infrastructure, which permits the University of Deusto to offer several laboratories to its students through the Internet [14]. Some available online experiments are:

- The iLab Shared Architecture (ISA) implemented by the MIT to facilitate the rapid development of new web laboratories and to provide a mechanism for students from one university to use the experiments and the hardware instruments of another university [15].

- VISIR is an open source laboratory dedicated to remote experimentations on analog electronics [16]. Some of the online experiments provided are: function generator and oscilloscope use, DC circuits, AC circuits or MOS transistor characterization.

- OCELOT (Open and Collaborative Environment for the Leverage of Online insTrumentation) is an open source and collaborative Online Laboratory framework and middleware. It is based on mixed reality and interactive multimedia. One of its core features is the multimodality of the W3C Widgets-based Graphic User Interface delivered to the learner. It is currently being implemented by Télécom Saint-Etienne (France) under LGPL (http://ocelot.ow2.org) [17].

- LiLa (stands for Library of Labs), a European eContentPlus project that promotes a portal of Online Labs resources and fosters exchanges on experiments among institutions [18]. To do this the using an elearning standard named SCORM. To do this, LiLa packs the remote laboratory in SCORM and use JavaScript to launch the experiments. Although this solution is able to use the laboratory, its main problem is that the exchange and storing of information between the SCORM package and of Lab is limited by the Javascript and the version of SCORM data model.

- Slab project Integration of open services for remote and virtual laboratories distributed, reusable and safe [7] [19-20]. It was developed by Electrical and Computer Engineering Department from UNED. The main goals were the use of remote labs in learning management systems, mobiles and the application of biometrics method with remote labs.

All these projects were focused on the use of "traditional" remote labs (Fig. 2) where each remote lab is shown as an indivisible e-learning component which provides a set of online experiments. The next section will describe a new way to 
understand remote labs and make easier the creation of elearning scenarios into different learning scenarios and environments.

\section{LEARNING SCENARIOS, SMART OBJECTS AND WIDGETS}

According to Klebl [21], "a learning scenario is a social setting dedicated to learning, education or training. It is a process of interaction between people in a specific learning situation using resources for learning within a designed environment. People in role of learners perform activities directed towards learning objectives using resources for learning. Learners may work won their own or in a group of learners. They may be supported by teaching staff”. Normally, these learning scenarios are composed of set of learning resources and activities, such as assessments, web pages, electronic files, forums, and remote labs. Moreover they are usually displayed in webpages or learning management systems [22].

Currently learning management systems are not the only way of displaying learning scenarios. Internet browser, mobile devices, tablets or social environments provide a software learning framework to design and create learning scenarios. For instance, google chrome provides a set of web applications which can be included and run from every device which supports Chrome (Fig. 3). These application are called App and they are miniature application views that can be embedded in other applications and receive periodic updates. Also, mobiles' operating system such as android works in a similar way (Fig. 4). Therefore a learning scenario could be a set of app focused on a determined learning goal.

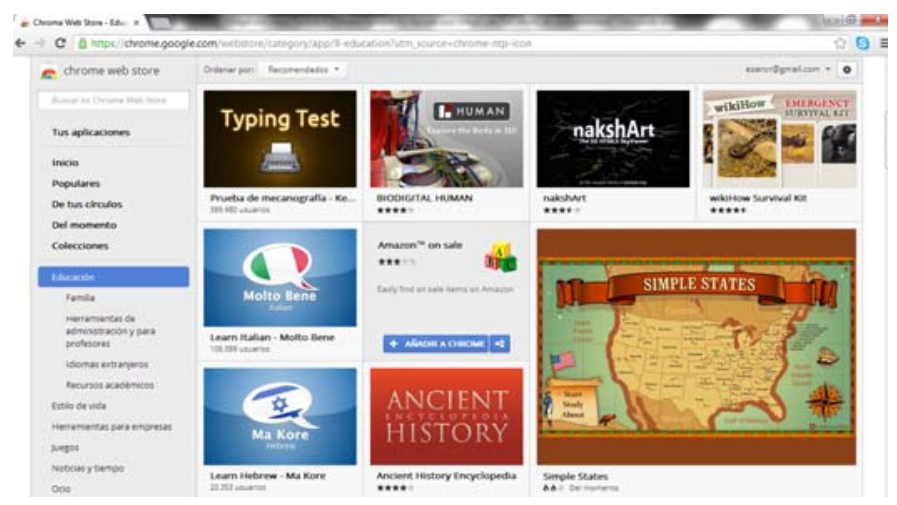

Figure 3. Web applications for Chrome web storage.

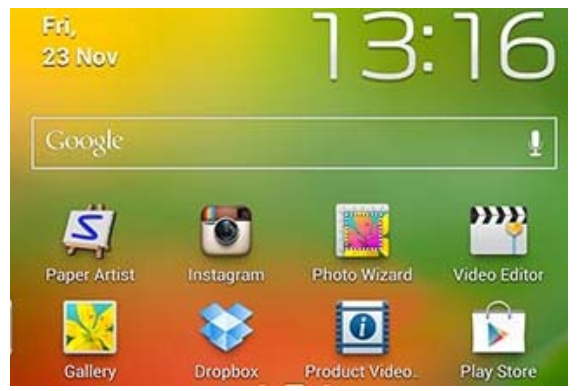

Figure 4. App Widgets for Android.
Chrome and android use native Apps, these can be converted to standardized format called W3C Widget [23-24].

\section{A. W3C widgets}

According to W3C "Widgets are full-fledged client-side applications that are authored using Web standards such as [HTML] and packaged for distribution. They are typically downloaded and installed on a client machine or device where they run as stand-alone applications, but they can also be embedded into Web pages and run in a Web browser" [25].

Widgets are packing in a valid Zip archive that contains the following:

- One configuration file called config.xml (casesensitive). This contains vital information about the widget, such as the name, author, description, license, and more.

- One or more start files, located at the root of the widget package and/or at the root of locale folders or referenced by a content element's src attribute. There are two kinds of start file: custom start file and default start file.

o A custom start file is a processable file inside the widget package identified by a content element's src attribute.

o A default start file is a reserved start file at the root of the widget package or at the root of a locale folder whose file name is index (casesensitively).

- Zero or more icons, either located at the root of the widget package and/or at the root of locale folders or referenced by the icon element's src attribute.

- Zero or more arbitrary files located either at the root of the widget package and/or in arbitrary folders or in locale folders.

- Zero or more digital signatures located at the root of the widget package.

An example of the structure of a widget package is shown in the figure 5 .

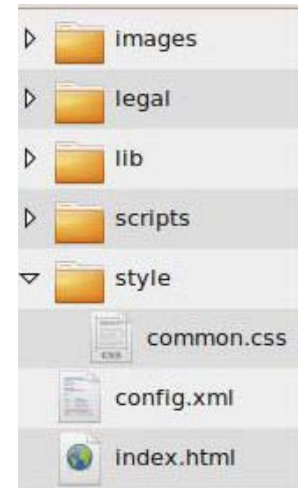

Figure 5. Widget package. 
These widgets can be stored and deployed through a widget engine such as google chrome or android (Fig. 3 and 4).

\section{B. Internet of things, Smart devices, remote labs and Widgets}

According to IEEE time machine "the Internet of Things (IoT) refers to the vision that in the next 20 years, a revolution in device-to-device communication will take place that will be comparable to the revolution in person-to-person communication that erupted in the last two decades with the Internet and World Wide Web.” [26].

Therefore, apart from e-learning content and applications, Internet is composed by a large range of hardware. This hardware will be directly connected to Internet and will be able to manage itself and communicate with other hardware. Also it can be embedded in widgets and displayed on World Wide Web. This hardware is called smart devices or objects.

As it was mentioned, remote labs are usually web applications which allow students to carry out online experiments and hand physical instruments. Therefore, Concepts such as smart devices and widgets should be considered on the design, development and implementation of remote labs (Fig 6).

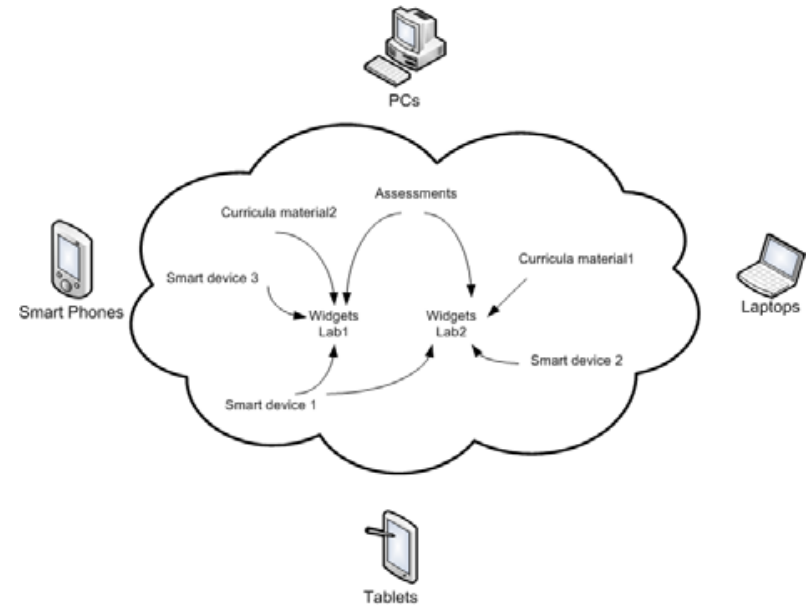

Figure 6. Creating remote labs through Widgets and smart devices.

The hardward's phrase (section 2), about software engineer as a key factor in the implementation of remote labs, can be solved with the use of widget. For instance a process to create a remote lab in learning scenarios can be described in the next steps:

1. Teacher should explain the components of remote labs and the experiments which can run.

2. The software engineer and technical group should design these components as a set of smart objects and widgets. Also they provide a toolkit editor to create the possible experiment. Not all the experiments need all the components (hardware). For instance, there will be electronic experiment where function generator or/and oscilloscope are not needed.
3. The teachers use the toolkit editor to create experiments and learning scenarios through a set of widgets (smart devices, application, curricula material, etc.).

4. These learning scenarios are deployed in the World Wide Web through a widget engine.

5. Students can access to these learning scenarios through different devices.

A key factor in this process is the design software and implementation of widgets (communication API between widgets and hardware, among widgets, etc.).

\section{CONCLUSION}

Concepts such as internet of things, smart devices and widgets are concepts which allow the reuse of hardware, elearning content and activities over Internet. Also it provides teachers with a new framework to create learning scenarios which can be implemented on different devices and platforms.

In the next decade many of the instruments of remote laboratories will be smart devices and object over internet. Even so, a long way must be walked. The use of e-learning standards, the split of functionalities between teachers and technical persons (software engineers) are challenges that have to be solved.

\section{ACKNOWLEDGMENT}

Authors would like to acknowledge the support of the following projects: e-Madrid (S2009/TIC-1650), RIPLECS (517836-LLP-1-2011-1-ES-ERASMUS-ESMO), PAC (517742-LLP-1-2011-1-BG-ERASMUS-ECUE), EMTM (2011-1-PL1-LEO05-19883), MUREE (530332-TEMPUS-12012-1-JO-TEMPUS-JPCR), and Go-Lab (FP7-ICT-20118/317601).

\section{REFERENCES}

[1] OpenCourseWare (OCW) http://ocw.mit.edu/index.htm consulted on september 2011

[2] SCORM (homesite). http://www.adlnet.gov/. Retrieved on 2011-10-10

[3] V. Gonzalez-Barbone and L. Anido-Rifon (2010). From SCORM to Common Cartridge: A step forward. Computers \& Education 54 (2010) 88-102.

[4] J. Garcia-Zubia et al (2007). "Remote laboratories from the software engineering point of view", Advances on Remote Labs and e-learning Experiences, Eds. Luis Gomes and Javier Garcia-Zubia, pp: 131-149, Ed. U. Deusto, ISBN: 978-84-9830-077-2J. Clerk Maxwell, A Treatise on Electricity and Magnetism, 3rd ed., vol. 2. Oxford: Clarendon, 1892, pp.68-73.

[5] C. Salzmann and D. Gillet From online experiments to smart devices, in International Journal of Online Engineering (iJOE), vol. Vol 4, num. special issue, REV2008.

[6] G. Kortuem, F. Kawsar, D. Fitton and V. Sundramoorthy. Smart Objects as Building Blocks for the Internet of Things. IEEE Internet Computing, Vol. 14, Issue: 1, 2010.

[7] E. Sancristobal "Methodology, structure and development of intermediate interfaces for connecting to remote labs and virtual learning platforms" in Spanish "Metodología, estructura y desarrollo de interfaces intermedias para la conexión de laboratorios remotos y virtuales a plataformas educativas" PhD thesis, UNED (Spanish University for Distance Education) 2010 
[8] de Jong, T. Computer Simulations - TechnologicalAdvances in Inquiry Learning. Science, 312, 532-533, 2006

[9] Ch.Salzmann; D. Gillet. Remote labs and social media: Agile aggregation and exploitation in higher engineering education. IEEE Global Engineering Education Conference (EDUCON). Jordan, 2011.

[10] D. Gillet; L-C. Effie Law and Arunangsu Chatterjee. Personal Learning Environments in a Global Higher Engineering Education Web 2.0 Realm. IEEE Global Engineering Education Conference (EDUCON). Madrid, 2010

[11] L. Gomes and S. Bogosyan, "Current Trends in Remote Laboratories," IEEE Trans. Ind. Electron., vol. 56, pp. 4744-4756, 2009.

[12] V. J. Harward, J. A. del Alamo, S. R. Lerman, P. H. Bailey, J. Carpenter, K. DeLong, C. Felknor, J. Hardison, B. Harrison, I. Jabbour, P. D. Long, M. Tingting, L. Naamani, J. Northridge, M. Schulz, D. Talavera, C. Varadharajan, W. Shaomin, K. Yehia, R. Zbib, and D. Zych, "The iLab Shared Architecture: A Web Services Infrastructure to Build Communities of Internet Accessible Laboratories," Proceedings of the IEEE, vol. 96, pp. 931-950, 2008.

[13] Labshare (homesite). Homesite at http://www.labshare.edu.au/home. Labshare project. consulted on september 2011

[14] Weblab-Deusto (homesite). Homesite https://www.weblab.deusto.es/web/ . consulted on september 2011

[15] iLab (homesite). Homesite at http://icampus.mit.edu/projects/iLabs.shtml. consulted on september 2011

[16] I. Gustavsson, et al, "On Objectives of Instructional Laboratories, Individual Assessment, and Use of Collaborative Remote Laboratories" IEEE Transactions on Learning Technologies, Vol.2, Nº.4, pp.263-274, October.-December. 2009
[17] C. Gravier and N. Abdellaoui, "Adaptive Follow-up of Online Engineering Laboratories Activities ", International Journal of online Engineering, vol. 6, $\mathrm{N}^{\circ}$ 3, pp. 32-37, august 2010

[18] Lila (homesite). Homesite at http://www.lila-project.org/. Lila resources. Retrieved on 2011-10-10 from http://www.lilaproject.org/resources/Documents/index.html .

[19] S. Martín. "M2LEARN: Framework for Development of Mobile and Ubiquitous Learning Applications" .Thesis, UNED (Spanish University for Distance Education) 2010

[20] R. Gil. "Autenticación por Huella Dactilar en Sistemas deGestión de Aprendizaje y su Análisis Empírico en Estudiantes de Ingeniería". Thesis, UNED (Spanish University for Distance Education) 2010

[21] M. Klebl. Educational interoperability standards: IMS learning design and DIN didactical object model.

[22] E. Sancristobal, M. Castro, J. Harward, P. Baley, K. DeLong, and J. Hardison, "Integration view of Web Labs and Learning Management Systems," IEEE Global Eng. Educ. Con. (EDUCON) 2010, pp. 14091417.

[23] Converting Chrome Installed Web Apps into W3C Widgetshttp://scottbw.wordpress.com/2011/02/17/converting-chromeinstalled-web-apps-into-w3c-widgets/ consulted on september 2011

[24] W3C Widget for android http://code.google.com/p/android-widget/ consulted on september 2011

[25] Packaged Web Apps (Widgets) - Packaging and XML Configuration (Second Edition) http://www.w3.org/TR/widgets/ consulted on september 2011

[26] the Ieee technology time machine http://www.ieee.org/documents/tech time machine.pdf consulted on september 2011 